\title{
DISCUSSIONS
}

\section{ANALYSIS OF TRACE ELEMENTS IN AIR-BORNE PARTICULATES, BY NEUTRON ACTIVATION AND GAMMA-RAY SPECTROMETRY}

Ir Is my impression that the authors* have salvaged useful information under rather less than ideal circumstances. Whereas the monitoring of trace elements in the atmosphere is an important duty, it is probably better to be done by idealizing the experiment somewhat more, so that the logical and reasonable relationships to meteorological variables can be established. I have the distinct impression that the esparto grass filters place serious limitations upon the study. If it could be based upon a more suitable filter, then smaller samples could be used and the real advantage of neutron-activation analysis, namely its ability to detect reliably much less than a microgram of any of the elements named, could be realized. In turn, relationships to weather parameters (the wind has been named, but there are others, such as precipitation especially) could be studied. Although the computer analysis of the $\gamma$-spectra is powerful enough to give useful results from relatively poor measurements, it is too bad to use these sophisticated techniques to save crude data. The initial data and the analysis should be of comparable sophistication in their respective departments, as it were.

The authors' technique of adjusting their standards on the assumption of constant reactor flux is also a weak point. Not only may the reactor flux vary over short times (such as cannot be timed accurately!) but the geometric relation of the sample in the rabbit to the neutron flux may introduce an additional variation. The measurements reported in this paper are sufficiently large that these errors may be tolerable: for a more demanding use of the technique, they probably would not be.

Dept. of Meteorology and Oceanography,

The University of Michigan, College of Engineering,

A. Nelson Dingle

Ann Arbor,

Mich. 48104, U.S.A.

* KeANe J. R. and Fisher E. M. R. (1968) Atmospheric Environment 2 (6), 603-614.

\section{AUTHORS' REPLY}

As POINTED out in the paper, other filters have certain advantages over esparto grass and are being-used in an investigation of pollution in an industrial area. Indeed the present paper publishes for the first time much of the essential information on which to base the choice of filter to suit the circumstances. However, esparto grass does have the advantage of permitting a large air flow without clogging or other damage and when the total performance is compared with other filters the superiority of the latter is less obvious.

There is an additional advantage in a large sample in that contamination through handling is minimised-an important consideration if reliance is to be placed on results of samples collected from a number of sites not all under the supervision of the analyst.

It is a misleading simplification to state only that the "real advantage . . . is to detect reliably much less than a microgram". Given a sufficiently low background filter and/or sufficient total air flow the limits of sensitivity are imposed by interference from other elements present in the sample of particulates and not by the theoretical sensivitity of neutron activation. It is for this reason that the computer analysis of the spectra is important and has nothing to do with the "saving of crude data".

Dr. DINGLE mentions one more weather parameter which could be considered. We agree that there are many studies to which the present technique could be applied. 